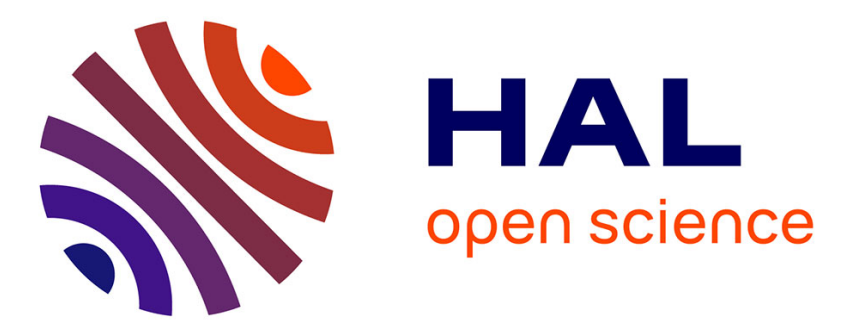

\title{
Residence time distribution in a biomass pretreatment reactor: Experimentation and modeling
}

\author{
Ziad Youssef, Fabrice F. Ducept, Hamdi Bennaceur, Barbara Malinowska,
} Giana Almeida, Patrick Perre, Denis Flick

\section{- To cite this version:}

Ziad Youssef, Fabrice F. Ducept, Hamdi Bennaceur, Barbara Malinowska, Giana Almeida, et al.. Residence time distribution in a biomass pretreatment reactor: Experimentation and modeling. Chemical Engineering Research and Design, 2017, 125, pp.233 - 244. 10.1016/j.cherd.2017.07.015 . hal01652569

\section{HAL Id: hal-01652569}

https://hal-centralesupelec.archives-ouvertes.fr/hal-01652569

Submitted on 17 Dec 2017

HAL is a multi-disciplinary open access archive for the deposit and dissemination of scientific research documents, whether they are published or not. The documents may come from teaching and research institutions in France or abroad, or from public or private research centers.
L'archive ouverte pluridisciplinaire HAL, est destinée au dépôt et à la diffusion de documents scientifiques de niveau recherche, publiés ou non, émanant des établissements d'enseignement et de recherche français ou étrangers, des laboratoires publics ou privés. 
Residence time distribution in a biomass pretreatment reactor: experimentation and modeling

Ziad YOUSSEF", Fabrice DUCEPT ${ }^{*}$, Hamdi BENNACEUR*, Barbara MALINOWSKA**, Giana ALMEIDA*, Patrick PERRE** and Denis FLICK*.

* UMR GENIAL, AgroParisTech, Inra, Université Paris-Saclay, 1 avenue des Olympiades, 91300 Massy, France.

** LGPM, CentraleSupelec, Université Paris-Saclay, Grande Voie des Vignes, 92290 Châtenay-Malabry, France.

\section{Graphical abstract}

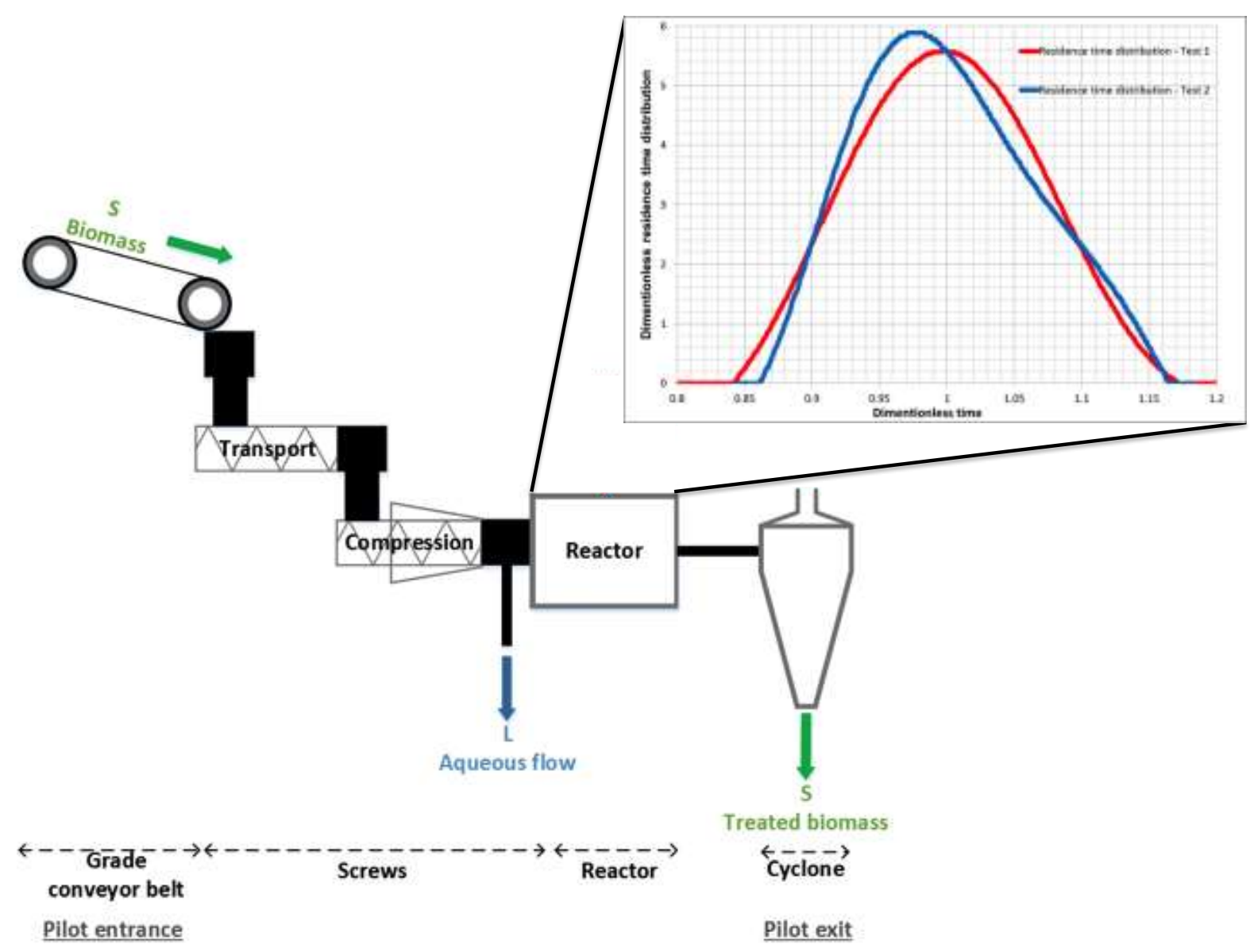




\title{
Highlights
}

- Biomass flow characterisation in a pretreatment reactor by using RTD experiments

- New methodology well adapted to the presence of acid and to severe thermodynamic conditions

- New type of tracers for the biomass pretreatment process

- Determination of the mean residence times in the reactor

- Modelling the residence time distribution

\begin{abstract}
The production of cellulosic bioethanol, one of the two main possibilities of second generation biofuels, involves four dependent steps: pretreatment, enzymatic hydrolysis, fermentation and distillation. This work concerns the first step which purpose is to modify the structure of the lignocellulosic biomass hence allowing cellulose to become more accessible to enzymatic hydrolysis. In this paper, the biomass flow is characterized in a pretreatment reactor. This is done by performing residence time distribution (RTD) experiments along with the use of new methodology well adapted to our system, industrial pilot plant presenting tough thermodynamic conditions. In this novel methodology, the tracer, sodium carbonate, reacts with the acidified biomass. Our protocol consists in measuring the variation of electrical conductivity and $\mathrm{pH}$ at the reactor entrance and exit. Two experiments were performed in the reactor for two different theoretical residence times. A chemical model was developed allowing the determination of tracer concentrations from the measured data. The experimental residence time distributions in the reactor, obtained by deconvolution, are well represented by using CSTR and axial dispersion models. The obtained results point out the nearly plug-flow behaviour of the pretreatment reactor.
\end{abstract}


Keywords: biomass; bioethanol; biofuel; pilot plant tests; residence time distribution and modeling. 


\section{Nomenclature}

\begin{tabular}{|c|c|}
\hline$F$ & Mass flow rate $\left(\mathrm{kg} \cdot \mathrm{s}^{-1}\right)$ \\
\hline$q$ & Volumetric flow rate $\left(\mathrm{m}^{3} \cdot \mathrm{s}^{-1}\right)$ \\
\hline$C_{x} \operatorname{or}[x]$ & Concentration of $\mathrm{x}\left(\mathrm{mol} \cdot \mathrm{m}^{-3}\right)$ \\
\hline$M$ & Molecular weight $\left(\mathrm{kg} \cdot \mathrm{mol}^{-1}\right)$ \\
\hline$\rho$ & Density $\left(\mathrm{kg} \cdot \mathrm{m}^{-3}\right)$ \\
\hline$V$ & Reactor volume $\left(\mathrm{m}^{3}\right)$ \\
\hline$m$ & Mass of added tracer $(\mathrm{kg})$ \\
\hline$v$ & Flow speed $\left(\mathrm{m} . \mathrm{s}^{-1}\right)$ \\
\hline$L$ & Reactor length (m) \\
\hline E & Residence time distribution function $\left(\mathrm{s}^{-1}\right)$ \\
\hline$E^{*}$ & Dimensionless residence time distribution (-) \\
\hline$S$ & Normalized concentration of $\mathrm{Na}^{+}\left(\mathrm{s}^{-1}\right)$ \\
\hline$t$ & Time (s) \\
\hline$\Theta$ & Normalized time (-) \\
\hline $\bar{t}$ & Mean residence time $(\mathrm{s})$ \\
\hline $\bar{t}_{g}$ & Geometrical residence time (s) \\
\hline$t_{\text {reactor }}^{\text {th }}$ & Theoretical residence time in the reactor (s) \\
\hline$t_{1}$ & Theoretical residence time for test $1(\mathrm{~s})$ \\
\hline$t_{2}$ & Theoretical residence time for test $2(\mathrm{~s})$ \\
\hline$t_{\text {aqueous flow }}$ & Average exit time of the aqueous flow (s) \\
\hline$t_{\text {belt }}$ & Average exit time out of the grade conveyor belt (s) \\
\hline$t_{\text {pilot }}$ & Average exit time out of the reactor and cyclone (s) \\
\hline$t_{\text {pilot first exit }}$ & First exit time out of the reactor and cyclone (s) \\
\hline
\end{tabular}


$t_{\text {screws first exit }}$

$t_{\text {step input }}$

$t_{\text {total exit pilot }}$

the cyclone (s)

$\Delta t_{\text {zone }}$

$D$

$N$

$P e$

$\lambda_{t}$

$\lambda_{x}^{m}$

$\varepsilon_{t}$

$n$

$n_{p}$

$n$

$\underline{\sigma}$

$y$

\section{Abbreviation}

$R T D$

PFR

CSTR

$A D M$
First exit time of the aqueous flow (s)

Tracer injection time into the pilot (s)

Needed time for the traced biomass to exit completely the reactor and

Zone duration

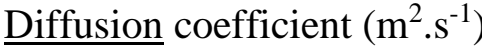

Amount of continuous flow stirred reactors (-)

Peclet number (-)

Measured conductivity $\left({\left.\mathrm{S} . \mathrm{m}^{-1}\right)}^{-1}\right.$

Molar conductivity of $\mathrm{x}\left(\mathrm{S} \cdot \mathrm{m}^{2} \cdot \mathrm{mol}^{-1}\right)$

Reaction advancement parameter (-)

Screw pitch

Number of screw pitch

Screw rotation speed

Variance (-)

Skewness (-)

Residence Time Distribution

Plug Flow Reactor

Continuous Flow Stirred Tank Reactor

Axial Dispersion Model 


\section{Introduction}

Bioethanol production based on second generation biomass is generally composed of four dependant steps: pretreatment, enzymatic hydrolysis, fermentation and distillation. The pretreatment process is composed of a succession of screws that are not all completely filled. Its main objective consists in modifying the structure of the cellulosic biomass in order to make cellulose more accessible to enzymatic hydrolysis step. Mosier et al. (2005) considered that the pretreatement objective is to break the lignin seal and disrupt the crystalline structure of cellulose. Pretreatment is required to modify the macroscopic and microscopic size and structure of the native biomass. Several pretreatments of lignocellulosic biomass can be found in the literature and the most widely used one is acid hydrolysis at high temperatures (Lee, Iyer et al. 1999, Wyman 1999).

The pretreatment of lignocellulosic biomass can contain up to three different treatments among which two are widely used (Lee, Iyer et al. 1999, Wyman 1999): acid washing followed by biomass cooking in a reactor.

The Residence Time Distribution (RTD) is a probability distribution function that represents the time a compound or fluid could spend inside a system (Danckwerts 1953, Danckwerts 1979). It is a useful technique to evaluate the performance of reactors. RTD can be experimentally determined by using inert tracers. By using such techniques, one can measure the tracer retention time which corresponds generally to the retention characteristics of the component. The used tracer should be easily detected, should not deteriorate under tough thermodynamic conditions, should not modify the viscosity of the system and should closely follow the component movement. For safety reasons, a neutral non-toxic compound is highly preferable. Finally, the price of the tracer may be an issue, especially for industrial applications where large amounts of tracer are needed to perform RTD experiments. 
Four main types of tracers were generally used in the literature depending on the application and on the phase of interest: radioactives (Moreno 1990), chlorides or salt type tracers such as $\mathrm{LiCl}$ or $\mathrm{NaCl}$ (Jeantet, Ducept et al. 2008, Levenspiel 1999), magnetics (Legile, Gonthier et al. 1991) and dyes (Arellano, Benkhelifa et al. 2013, Gupta, Yang et al. 2004, Ileri and Muslu 1996).

In the literature, many authors (Bi and Jiang 2009, Gao, Walsh et al. 1999, Kumar, Vercruysse et al. 2015, Lee, Park et al. 2005, Nachenius, van de Wardt et al. 2015, Sievers, Kuhn et al. 2016) studied residence time distribution in screws, mostly for food production and bioenergy applications. Nachenius et al. (2015) confirmed that despite the widespread application of screw conveyors, their understanding remains largely empirical. Bi and Jiang (2009) studied RTD in a single screw pin barrel extruder and used a dye compound as a tracer. Nachenius et al. (2015) analyzed residence time distribution in rotating screw conveyors on three components: air-dried pine chips, dehulled rice and quartz sand. In their experiments, they replaced the use of a classical tracer by imposing a step change in the bulk flow rate at steady-state conditions and RTD was then determined as function of the outlet flow rates until the reach of a new steady state. Some authors in the literature (Gao, Walsh et al. 1999, Kumar, Vercruysse et al. 2015, Lee, Park et al. 2005) studied RTD of a twin-screw granulation system that consists of transport and kneading elements. These authors respectively used the following tracers or tracking techniques: titanium dioxide, pellet type of compounded $\mathrm{CaCO}_{3}$ in polymer and positron emission particle tracking. Sievers et al. (2016) used $\mathrm{NaCl}$ as a tracer to analyse residence time distribution in a succession of screws. They found that soluble and insoluble compounds travel at the same rates in a horizontal auger tube reactor thus there is no liquid/solid stratification. In their work, the biomass consisted of corn stover that was hammer milled and had previously endured two distinct treatments: acid washing and thermal treatment by using saturated water steam at around $200{ }^{\circ} \mathrm{C}$. Xi et al. 
(2015) performed the same study as Sievers et al. (Sievers, Kuhn et al. 2016) by using a similar system: a horizontal stirred bed reactor. They tested three different types of biomass: wood (both cubic and irregular shapes), corn cob and soybean. Coloured particles were used as a tracer for the first two biomasses and red beans for the third biomass. Table 1 summarizes some RTD studies concerning screws. Most of the studies used impulse input for tracer injection. 
Table 1 - Summary of the main screw systems of the literature.

\begin{tabular}{|c|c|c|c|c|c|c|c|}
\hline Reference & Scale & Component & Tracer & $\begin{array}{l}\text { Tracer } \\
\text { injection }\end{array}$ & Reactor & $\begin{array}{l}\text { Thermal } \\
\text { treatment } \\
\left(\mathrm{T}>160^{\circ} \mathrm{C}\right)\end{array}$ & Application \\
\hline $\begin{array}{l}\text { Bi and Jiang } \\
\text { (2009) }\end{array}$ & \multirow{4}{*}{ Laboratory } & Polymer & $\begin{array}{l}\text { Dye (red dye } \\
\text { and } \\
\text { matrix } \\
\text { material) }\end{array}$ & \multirow{4}{*}{ Impulse } & \multirow{4}{*}{$\begin{array}{l}\text { Single or } \\
\text { twin screw } \\
\text { extruders }\end{array}$} & No & \multirow{4}{*}{$\begin{array}{l}\text { Food } \\
\text { production }\end{array}$} \\
\hline $\begin{array}{l}\text { Gao et al. } \\
(1999)\end{array}$ & & Polyethylene & Dye $\left(\mathrm{TiO}_{2}\right)$ & & & No & \\
\hline $\begin{array}{l}\text { Lee et al. } \\
(2005)\end{array}$ & & Polymer & $\begin{array}{l}\mathrm{CaCO}_{3} \text { filled } \\
\text { in polymer }\end{array}$ & & & Yes & \\
\hline $\begin{array}{l}\text { Kumar et al. } \\
\text { (2015) }\end{array}$ & & $\begin{array}{l}\text { Wet } \\
\text { granulation }\end{array}$ & $\begin{array}{l}\text { Dye (spiking } \\
\text { anhydrous } \\
\text { theophylline) }\end{array}$ & & & No & \\
\hline $\begin{array}{l}\text { Sievers et al. } \\
(2016)\end{array}$ & Industrial & $\begin{array}{l}\text { Biomass } \\
\text { (corn stover) }\end{array}$ & Salt $(\mathrm{NaCl})$ & Impulse & $\begin{array}{l}\text { Auger } \\
\text { screw }\end{array}$ & Yes & \\
\hline $\begin{array}{l}\text { Nachenius } \\
\text { et al. (2015) }\end{array}$ & Laboratory & $\begin{array}{l}\text { Biomasses } \\
\text { (air-dried } \\
\text { pine chips, } \\
\text { dehulled rice } \\
\text { and quartz } \\
\text { sand) }\end{array}$ & $\begin{array}{l}\text { Imposing a } \\
\text { step change of } \\
\text { flow rate }\end{array}$ & $\begin{array}{l}\text { Step } \\
\text { imput }\end{array}$ & $\begin{array}{l}\text { Screw } \\
\text { conveyors }\end{array}$ & No & $\begin{array}{l}\text { Bioethanol } \\
\text { production }\end{array}$ \\
\hline $\begin{array}{l}\text { Xi et al. } \\
\text { (2015) }\end{array}$ & Industrial & $\begin{array}{l}\text { Biomasses } \\
\text { (wood, corn }\end{array}$ & $\begin{array}{l}\text { Dye } \quad \text { (red } \\
\text { bean) }\end{array}$ & Impulse & $\begin{array}{l}\text { Horizontal } \\
\text { stirred bed }\end{array}$ & & $\begin{array}{l}\text { Renewable } \\
\text { biomass }\end{array}$ \\
\hline
\end{tabular}


soybean)

As seen in Table 1, most of the residence time distribution studies were carried out without thermal treatment and were performed at laboratory scale.

The previously cited articles provide knowledge of the parameters that can impact residence time distributions. Bi and Jiang (2009) and Xi et al. (2015) showed that mean residence time depends on the screw speed: it increases with the decrease of the screw rotation speed. Nachenius et al. (2015) has shown that the mean residence time increases with the increase of the degree of filling. Also, it was logically observed by many scientifics that the mean residence time is significantly longer than the theoretical imposed one that only depends on screw rotation speed (Bi and Jiang 2009, Gao, Walsh et al. 1999, Kumar, Vercruysse et al. 2015, Lee, Park et al. 2005, Nachenius, van de Wardt et al. 2015, Sievers, Kuhn et al. 2016, Xi, Chen et al. 2015).

In this work, a new methodology was developed to determine the residence time distribution during the pretreatment process of wheat straw by using a new type of salt tracer, sodium carbonate $\left(\mathrm{Na}_{2} \mathrm{CO}_{3}\right)$. It is the first time that such tracer is applied on treated lignocellulosic biomass. This tracer was specifically chosen because of the tough thermodynamic conditions in the industrial pilot plant (high temperature and pressure). The specificity of this work consists in the reaction between the tracer and the acid found in the biomass. Such reaction was not previously studied in the literature. In addition, the RTD was performed during the thermal treatment of the biomass. To our knowledge, there is very little information in the literature regarding RTD analyses at industrial scale that are performed under similar severe process and thermodynamic conditions (acidity, temperature level and saturated steam). Thus 
a new methodology was developed to overcome that difficulty. It consists in the measurements of $\mathrm{pH}$ and electrical conductivity at two different locations of the process: at the reactor entrance and its exit. These two complementary measurements were necessary to determine the tracer concentration as function of time which indirectly leads to the RTD curves. Our results provide important knowledge of the real time spent by the component in the reactor, which allows the determination of the variability of cooking in the reactor. Thus this work provides a better understanding of the pretreatment process and can also be used to better size future operating units.

\section{Material and methods}

In our experiments, the biomass consisted of wheat straw (milling wheat, cultivated in 2014 in the North of France) that was previously grinded to $20 \mathrm{~mm}$.

\subsection{Description of the pretreatment process}

The pretreatment section is divided into two parts: acid impregnation of the biomass and thermal processing.

Acid impregnation of the biomass consisted of a batch impregnation carried out in $1 \mathrm{~m}^{3}$ containers at atmospheric pressure. During this process, a highly diluted aqueous solution of sulfuric acid was added to the previously grinded native biomass. Acid fraction in the aqueous solution was between 0.5 and 1.0 wt. \%. The system was kept in contact for 20 hours at room temperature. Each container was connected to a valve allowing to drain the liquid phase. At the end, the remaining compound in the containers was a wet solid biomass. It is afterward introduced to the process by using the grade conveyor belt. Then, it was transported and compressed in a succession of screws as shown in Fig. 1. 


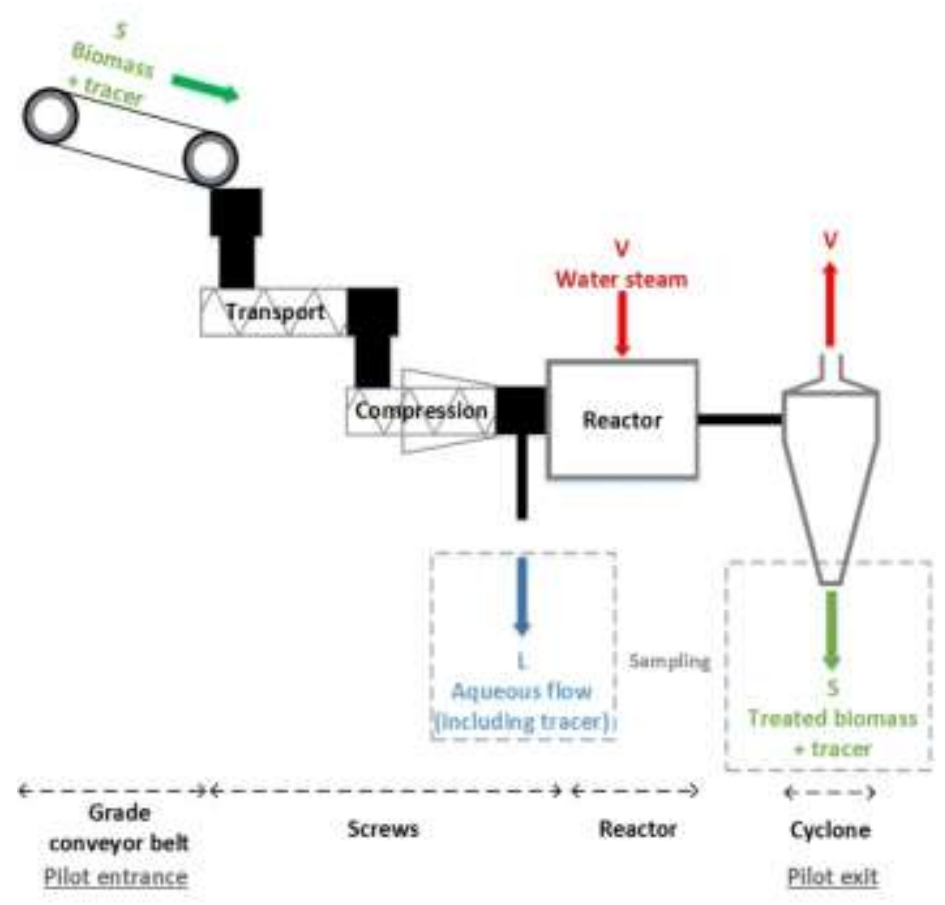

Fig. 1 - Process flow diagram of the pretreatment pilot.

At the exit of the compressing screw, the biomass lost a big amount of its water that exited the process. In this paper, this liquid phase is called aqueous flow. The reactor was composed of one screw that controls the theoretical residence time. Its volume is around $0.2 \mathrm{~m}^{3}$. In the reactor, the biomass has undergone the thermal treatment that was ensured by the injection of saturated water steam. Once the biphasic system (vapor water steam-biomass) left the reactor, the different phases were separated in a cyclone. The solid phase, the treated biomass, was recovered at the bottom of the cyclone and the vapor phase on its top.

\subsection{Choice of the tracer}

In this work, it was decided to use a salt type tracer for the RTD experiments. Such tracers have the advantage of being well studied in the literature, are relatively cheap, have very little environmental impact and can be easily supplied even in large amounts. At the same time, these tracers can be easily detected, their use is simple and it does not require a modification in the process (in contrary to the spectroscopic methods). Thus four salt type tracers from 
Sigma-Aldrich were analyzed and compared to each other: sodium nitrate $\left(\mathrm{NaNO}_{3}\right.$, purity of 99.0 wt. \%), sodium chloride $\left(\mathrm{NaCl}, 99.5\right.$ wt. \%), sodium carbonate $\left(\mathrm{Na}_{2} \mathrm{CO}_{3}, 99.8\right.$ wt. \%) and Sodium bicarbonate $\left(\mathrm{NaHCO}_{3}, 99.0\right.$ wt. \%). The comparison was based on six aspects: the measured conductivity (experimental), mass solubility in water (data from sigma Aldrich), risks on humans (retrieved from Sigma-Aldrich), melting temperature values (taken from Hazardous Substances Data Bank data), corrosivity on stainless steel and reaction with sulphuric acid $\left(\mathrm{H}_{2} \mathrm{SO}_{4}\right)$. The results are summarized in Table 2.

Table 2 - Comparison between four salt type tracers.

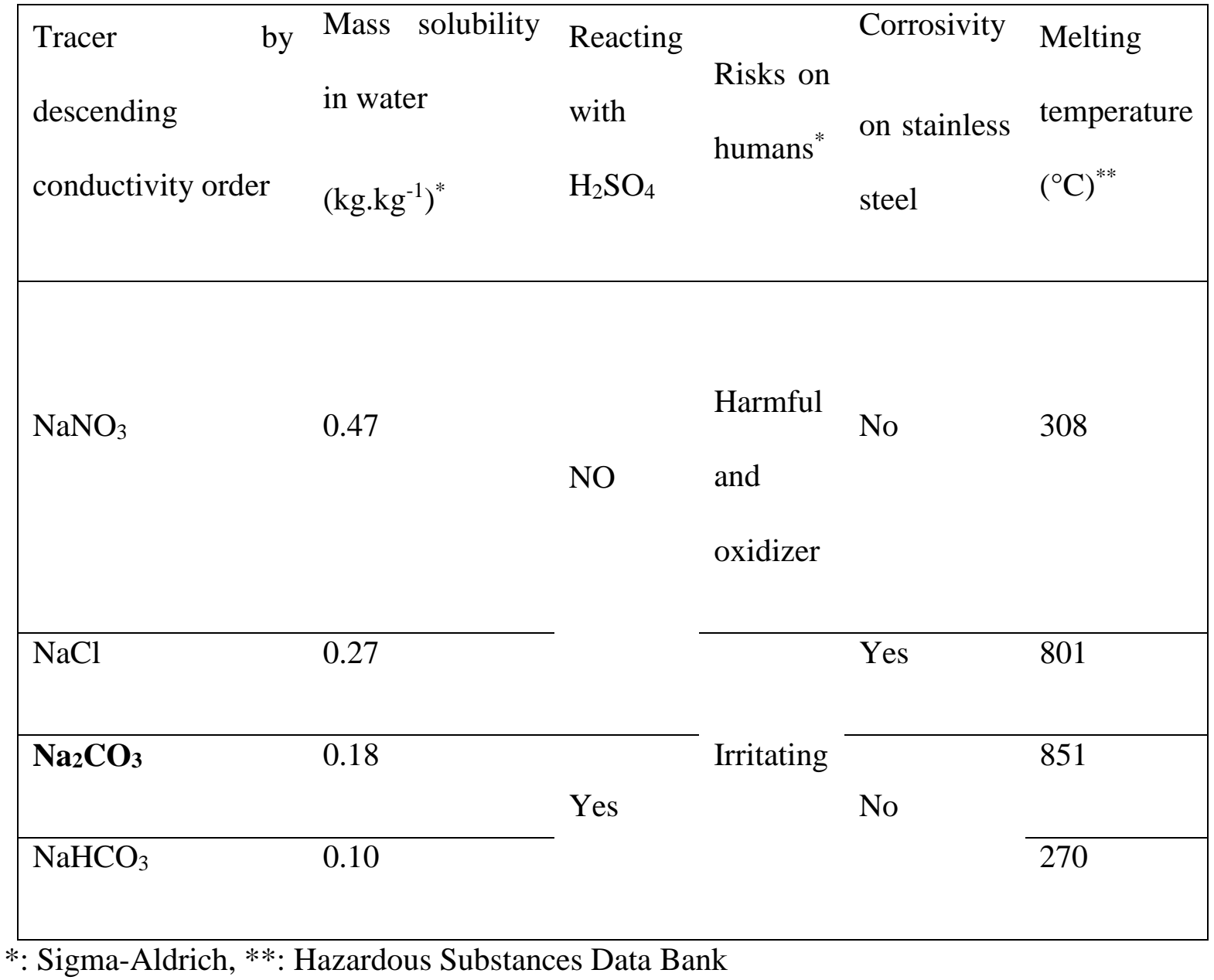

Based on Table 2, sodium nitrate was excluded mainly because it is harmful. Sodium chloride was also excluded because of its high corrosivity on stainless steel especially at high temperatures. On the other hand, sodium carbonate has a higher conductivity and solubility in 
water than sodium bicarbonate. Thus it was decided to use sodium carbonate as a tracer for the residence time distribution experiments. However, the main disadvantage of sodium carbonate is its reaction with sulfuric acid.

\subsection{Measurements accuracy}

\section{Conductivity meter}

The used conductivity meter is a SENSION+EC5 model from Hach. It allows the measurements of ionic conductivities in the solutions even under tough thermodynamic conditions and in the presence of acid. Its measuring range varies from $1 \mu \mathrm{S} . \mathrm{cm}^{-1}$ up to 1 S.cm ${ }^{-1}$. The conductivity meter was calibrated by comparison to a reference solution. The accuracy is better than $1 \%$.

\section{pH meter}

The $\mathrm{pH}$ meter is a portable model (Hanna, HI 98128) that can measure $\mathrm{pH}$ values between 0.1 and 13.9. Before the measurements, the device was calibrated with a buffer solution. The measurement accuracy is around $0.01 \mathrm{pH}$ unit.

\subsection{Operating procedure}

\subsubsection{Preparation of the traced biomass}

Preliminary tests carried out in the laboratory allowed to determine the optimum tracer mass fraction in the biomass, which is around $6 \mathrm{wt} . \%$. In order to reach this fraction, a small part of the biomass (10 kg, previously impregnated with acid) was mixed with $600 \mathrm{~g}$ of the tracer.

\subsubsection{Tracer introduction}

In order to well establish the steady state in the reactor, a succession of steps was used. The first step consists in heating up the empty reactor by injecting water steam. Once the desired temperature in the reactor is obtained and the steady state is reached, solid compounds can be 
$\underline{\text { introduced to the process from the grade conveyor belt. At first, the added biomass is tracer }}$ free. The presence of the biomass in the pilot will cool down the water steam in the reactor and hence an additional time is required to stabilize again the reactor temperature. Once this is achieved, the traced biomass is introduced to the conveyor belt. It is deposited along two meters of the belt. This way, non-traced and the traced feedstock were introduced continuously to the system, without any break. The tracer introduction time into the pilot is 69 seconds $\left(t_{\text {step input }}\right)$. The type of tracer introduction is a step input because it is not instantly added. The beginning of the measurements $(t=0)$ correspond to the moment where the first particle of traced biomass is introduced into the first screw of the process. It is important to note that the traced and untraced biomass had initially the same acid fraction.

\subsubsection{Conductivity and $\mathrm{pH}$ measurements}

Afterwards, electrical conductivity and $\mathrm{pH}$ measurements were performed at two distinct locations: at the aqueous flow and cyclone exits. They were respectively measured by using a conductivity meter and a $\mathrm{pH}$ meter that were preliminary calibrated.

\section{Measurements at the aqueous flow}

For the aqueous flow, the $\mathrm{pH}$ was measured continuously and directly. The conductivity was measured later in the laboratory on the aqueous flow samples which were collected every 10 seconds.

\section{Measurements at the cyclone exit}

The measurements at the cyclone exit were performed later on in the laboratory on the biomass samples collected every $20 \mathrm{~s}$. During that time, around two kilograms of biomass was collected. For each sample, a solution composed of $10 \mathrm{wt} . \%$ of treated biomass and $90 \mathrm{wt} . \%$ of distilled water were prepared. They were let to rest for 24 hours at room temperature in 
order to stabilize the electrical conductivity. Then, the conductivity and $\mathrm{pH}$ of that liquid phase were measured at constant room temperature (around $23{ }^{\circ} \mathrm{C}$ ).

It has to be mentioned that although the reactor operated at reaction temperatures and with acid, the tracer was neutralizing the catalytic effect of the sulfuric acid. Thus the traced particles size was modified which can affect the flow of these less treated particles and therefore affect the shape of the measured RTD. Nevertheless, the granulometry (not presented here) of particles treated with different amounts of sulfuric acid remained of the $\underline{\text { same order and the apparent density was quite not modified. }}$

\section{Theory}

\subsection{Modeling the tracer concentration}

In general, while performing classical Residence Time Distribution (RTD) experiments with ionic tracers, the only conductive component in the system (when the conductivity of the native component is neglected) is the tracer and hence the measured conductivity corresponds to the tracer conductivity. In that case, it would be easy to use the preliminary determined calibration curve, i.e. conductivity as function of tracer concentration, in order to deduce the corresponding tracer concentration as function of the time. However, our system is more complicated because of the presence of different ionic species. The used tracer reacts with sulfuric acid through the main reaction shown in Eq 1, to produce sodium sulfate $\left(\mathrm{Na}_{2} \mathrm{SO}_{4}\right)$, liquid water and vapor carbon dioxide.

$$
\mathrm{H}_{2} \mathrm{SO}_{4}+\mathrm{Na}_{2} \mathrm{CO}_{3} \rightarrow \mathrm{Na}_{2} \mathrm{SO}_{4}+\mathrm{H}_{2} \mathrm{O}+\mathrm{CO}_{2}(\mathrm{~V})
$$

It is important to note that $\mathrm{Na}_{2} \mathrm{SO}_{4}$ has a neutral $\mathrm{pH}$ when it is diluted in water and that $\mathrm{Na}+$ is initially only found in the tracer. The reaction presented in Eq 1 is not a total reaction and its advancement is characterized by the reaction advancement parameter $\varepsilon_{t}$. Based on Eq 1, the following ions are found in the system: $\mathrm{Na}^{+}, \mathrm{H}_{3} \mathrm{O}^{+}, \mathrm{CO}_{3}^{2-}$ and $\mathrm{So}_{4}^{2-}$. They result respectively 
from the complete dissociation in water of the following compounds: $\mathrm{Na}_{2} \mathrm{CO}_{3} / \mathrm{Na}_{2} \mathrm{SO}_{4}$, $\mathrm{H}_{2} \mathrm{SO}_{4}, \mathrm{Na}_{2} \mathrm{CO}_{3}$ and $\mathrm{H}_{2} \mathrm{SO}_{4}$.

So, the measured conductivity at time $\mathrm{t}\left(\lambda_{t}\right)$ is the sum of all the partial conductivities including that of the native (untreated) biomass $\left(\lambda_{N B}\right)$ as depicted in Eq 2.

$$
\lambda_{t}=\lambda_{\mathrm{NB}}+\lambda_{\mathrm{H}_{3} \mathrm{O}^{+}}+\lambda_{\mathrm{SO}_{4}^{2-}}+\lambda_{\mathrm{Na+}}+\lambda_{\mathrm{CO}_{3}^{2-}}
$$

For each ionic species $i$, its partial conductivity is the product of its concentration $[i]_{t}$ and its molar conductivity $\lambda_{i}^{m}$. Eq 2 can then be rewritten (Eq 3$)$.

$\lambda_{t}=\lambda_{N B}+\left[\mathrm{H}_{3} \mathrm{O}^{+}\right]_{t} \lambda_{\mathrm{H}_{3} \mathrm{O}^{+}}^{m}+\left[\mathrm{SO}_{4}^{2-}\right]_{t} \lambda_{S O_{4}^{2-}}^{m}+\left[\mathrm{Na}^{+}\right]_{t} \lambda_{\mathrm{Na}^{+}}^{m}+\left[\mathrm{CO}_{3}^{2-}\right]_{t} \lambda$ Eq 3

The concentration of $\mathrm{H}_{3} \mathrm{O}^{+},\left[\mathrm{H}_{3} \mathrm{O}^{+}\right]_{t}$, is obtained directly as function of the measured $\mathrm{pH}$ or as function of the reaction advancement parameter (Eq 4). The concentration of $\mathrm{SO}_{4}^{2-}$ is equal to that of acid in the untraced biomass $\left[\mathrm{H}_{\mathbf{2}} \mathrm{SO}_{\mathbf{4}}\right]_{0}$. Before the beginning of the reaction (Eq 1), the concentration of $\mathrm{CO}_{3}^{2-},\left[\mathrm{CO}_{3}^{2-}\right]_{t}$, is half of that of $\mathrm{Na}^{+}$. It decreases as function of $\varepsilon_{t}$. So, the concentrations given in Eq 3 can be reformulated as shown in Eq 4.

$$
\begin{aligned}
& {\left[\mathrm{H}_{3} \mathrm{O}^{+}\right]_{t}=2\left[\mathrm{H}_{2} \mathrm{SO}_{4}\right]_{0}\left(1-\varepsilon_{t}\right)=1000 \cdot 10^{-p H_{t}}} \\
& {\left[\mathrm{SO}_{4}^{2-}\right]_{t}=\left[\mathrm{H}_{2} \mathrm{SO}_{4}\right]_{0}} \\
& {\left[\mathrm{CO}_{3}^{2-}\right]_{t}=\frac{\left[\mathrm{Na}^{+}\right]_{t}}{2}-\varepsilon_{t}\left[\mathrm{H}_{2} \mathrm{SO}_{4}\right]_{0}}
\end{aligned}
$$

In Eq 4, the factor 1000 is added in order to express the concentration in mol.m $\mathrm{m}^{-3}$.

Based on Eq 3and Eq 4, the concentration of $\mathrm{Na}^{+}$as function of time is thus represented in $\mathrm{Eq}$ 5. 
$\left[\mathrm{Na}^{+}\right]_{t}=\frac{\lambda_{t}-\lambda_{N B}-\left[\mathrm{H}_{2} S \mathrm{~S}_{4}\right]_{0}\left(-\varepsilon_{t} \lambda_{\mathrm{CO}_{3}^{2-}}^{m}+\left(2-2 \varepsilon_{t}\right) \lambda_{\mathrm{H}_{3} \mathrm{O}^{+}}^{m}+\lambda_{\mathrm{SO}_{4}^{2-}}^{m}\right)}{\lambda_{\mathrm{Na}^{+}}^{m}+0.5 \lambda_{\mathrm{CO}_{3}^{2-}}^{m}}$

Eq 5

On the other hand, in the absence of tracer, the total conductivity $\left(\lambda^{*}\right)$ only depends on the concentrations of $\mathrm{H}_{3} \mathrm{O}^{+},\left[\mathrm{H}_{3} \mathrm{O}^{+}\right]_{0}$, and $\mathrm{SO}_{4}^{2-},\left[\mathrm{SO}_{4}^{2-}\right]_{0}$, or on that of $\mathrm{H}_{2} \mathrm{SO}_{4},\left[\mathrm{H}_{\mathbf{2}} \mathrm{SO}_{4}\right]_{0}$, as given in Eq 6.

$\lambda^{*}=\lambda_{N B}+\left[H_{3} O^{+}\right]_{0} \lambda_{H_{3} O^{+}}^{m}+\left[S O_{4}^{2-}\right]_{0} \lambda_{S O_{4}^{2-}}^{m}=\left[H_{2} S_{4}\right]_{0}\left(2 \lambda_{H_{3} O^{+}}^{m}+\lambda_{S O_{4}^{2-}}^{m}\right)$

Eq 6

The measured $\mathrm{pH}$ in the absence of tracer, $p H^{*}$, is also directly related to the acid concentration in the untraced biomasse.in the presence of tracer, $p H_{t}$, and on that in the absence of tracer, $p H^{*}(\mathrm{Eq} 7$ and $\mathrm{Eq} 8)$.

$\left[\mathrm{H}_{2} \mathrm{SO}_{4}\right]_{0}=\frac{1000 \cdot 10^{-p H^{*}}}{2}$

Eq 7

Based on Eq 4 and $\mathrm{Eq} 7$, it is now possible to calculate the reaction advancement parameter as function of the $\mathrm{pH}$ as shown in $\mathrm{Eq} 8$.

$\varepsilon_{t}=1-\frac{1000 \cdot 10^{-p H_{t}}}{1000 \cdot 10^{-p H^{*}}}=1-10^{p H^{*}-p H_{t}}$

Eq 8

By considering three previous equations (Eq 5, Eq 6 and Eq 8), the final expression of $\left[\mathrm{Na}^{+}\right]_{\mathrm{t}}$ as function of the measured $\mathrm{pH}$ and conductivity is hence presented in $\mathrm{Eq} 9$. 
$\left[N a^{+}\right]_{t}=\frac{\lambda_{t}-\lambda_{N B}-\frac{\lambda_{t o t}^{*}}{2 \lambda_{H_{3} O^{+}}^{m}+\lambda_{S O_{4}^{2-}}^{m}}\left[\left(10^{\left.\left.p H^{*-p H_{t}}-1\right) \lambda_{\mathrm{CO}_{3}^{2-}}^{m}+\left(2 \cdot 10^{p H^{*-p} p H_{t}}\right) \lambda_{H_{3} O^{+}}^{m}+\lambda_{S O_{4}^{2-}}^{m}\right]}\right.\right.}{\lambda_{\mathrm{Na}^{+}}^{m}+0.5 \lambda_{\mathrm{CO}_{3}^{2-}}^{m}}$

\subsection{RTD determination}

In this work, it was decided to consider the concentration of $\mathrm{Na}^{+},\left[\mathrm{Na}^{+}\right]_{t}$, instead of that of the

tracer, $\left[\mathrm{Na}_{2} \mathrm{CO}_{3}\right]_{t}$, for the following reasons: first of all, $\mathrm{Na}^{+}$is not present in the untraced biomass and secondly it remains in the system during the reaction between sodium carbonate and acid.

Therefore, we consider the normalized $\mathrm{Na}^{+}$concentrations at different positions in the process as defined in Eq 10.

$$
S(t)=\frac{\left[N a^{+}\right]_{t}}{\int_{0}^{\infty}\left[N a^{+}\right] d t}
$$

The residence time distribution function $E$ is equal to the normalized tracer exit concentration only in the case of impulse injections. This is not case in the present work because the tracer was added to the process in step input injection mode with a non-negligible injection time. Therefore, signal deconvolution was necessary to obtain the RTD function.

Sodium concentration was determined as function of the measured conductivity and $\mathrm{pH}$ at two distinct locations in the process by using $\mathrm{Eq}$ 9: at the aqueous flow and the reactor/cyclone exits. Afterwards, the normalized aqueous flow and reactor/cyclone exit signals (respectively $S_{\text {aqueous flow }}$ and $\left.S_{\text {pilot }}\right)$ were determined based on Eq 10. The residence time distribution in the reactor $(E)$ can be determined by deconvolution as given in Eq 11 (Levenspiel 1999). 
$S_{\text {pilot }}=S_{\text {aqueousflow }} \otimes E$

In this work, the aqueous flow signal is assimilated to the reactor entrance signal.

Afterwards, RTD function was deduced by using an already predefined deconvolution function in matlab based on Fourier transform. The Fourier transform of $E$ is obtained by dividing Fourier transform of $S_{\text {pilot }}$ by the one of $S_{\text {aqueousflow after filtering the highest }}$ frequencies.

The mean residence time, $\bar{t}$, is defined by Eq 12 as the first order moment of $E$ (Levenspiel 1999). It is an important parameter that quantifies the flow behaviour.

$\bar{t}=\int_{0}^{\infty} t E(t) d t=\frac{\text { Mass inventory in the system }}{\text { Mass flow rate through the system }}=\frac{\text { Hold }- \text { up }}{\text { Throughput }}$

In this work, we determined the mean residence time in the reactor and in the cyclone. However, the mean residence time in the cyclone can be neglected $(<2 s)$ thus the determined mean residence time is assimilated to that in the reactor.

The variance $(\sigma)$ and the skewness $(\gamma)$ can also be directly calculated (Eq 13) from the deconvoluted RTD curves (Fig. 8).

$\sigma^{2}=\int_{0}^{\infty}(\Theta-1)^{2} E^{*} d \Theta \quad$ and $\quad \gamma=\int_{0}^{\infty} \frac{(\Theta-1)^{3} E^{*} d \Theta}{\sigma^{3}}$

where $\Theta$ and $E^{*}$ are respectively the normalized time and the normalized residence time distribution.

3.3 Modeling the RTD signal 
There are mainly four types of flow models that characterize reactors: Plug Flow Reactor (PFR), Continuous Flow Stirred Tank Reactor (CSTR), Axial Dispersion Model (ADM) and the non-ideal reactor models that are the combinations of the first three models (Davis and Davis 2003). CSTR and PFR models are two extreme ideal cases so most likely the real behaviour is between both of them. Plug flow reactor was well described by Danckwerts (1953) as the behaviour that represents elements of fluids that enter the vessel at the same time and move through it with constant and equal velocity by using parallel paths and leave it at the same time. The same author considered that the CSTR behaviour occurs when the fluid in the vessel is completely mixed and that its properties are uniform and equal to those of the outgoing stream.

In this work, the experimental residence time distributions were compared with two different non-ideal models: CSTR in series and ADM.

\subsubsection{CSTR in series}

The RTD expression for a series of $\mathrm{N}$ continuous flow stirred tank reactor model is given in Eq 14.

$$
E *(\Theta)=\frac{N(N \Theta)^{N-1}}{(N-1) !} e^{-N \Theta}
$$

The normalized time and the normalized residence time distribution are provided in Eq 15.

$$
E^{*}=\bar{t} \text { and } \Theta=\frac{t}{t}
$$

The CSTR model can be adjusted as function of $N$. This model can be considered equivalent to PFR when $N$ tends towards infinity. 
For high $N$ values $(\mathrm{N}>100)$, the CSTR model can be very accurately approached by a Gaussian function as shown in Eq 16.

$E *(\Theta)=\sqrt{\frac{N}{2 \pi}} e^{\frac{-N(\Theta-1)^{2}}{2}}$

Eq 16

where $\frac{\mathbf{1}}{N}$ represents the variance.

By using Eq 16, the peak of the RTD function is obtained for $\Theta=1$ and hence the RTD peak corresponds to $\frac{\sqrt{n}}{2 \pi}$. Thus the optimal value of $N, N_{\text {opt }}$, is determined as function of the experimental RTD peak (Eq 17). It allows the model to fit the experimental data.

$N_{o p t} \approx 2 \pi E_{\max }^{2}$

Eq 17

\subsubsection{Axial dispersion model}

The open vessel axial dispersion model is represented in Eq 18. The open vessel condition was chosen because it represents well the studied system.

$E *(\Theta)=0.5\left(\frac{P e}{\pi \Theta}\right)^{0.5} e^{\left[\frac{-P e(1-\Theta)^{2}}{4 \Theta}\right]}$

Eq 18

In Eq 18, Pe is the Peclet number. For a simple tube flow, its expression is represented in Eq 19. It depends on the flow speed $v$, the tube length $L$ and on the diffusion coefficient, $D$, that represents this spreading process.

$P e=\frac{L v}{D}$

Eq 19 
This model can be fitted to the experimental RTD by modifying the Peclet number. When the diffusion coefficient is close to zero, the Peclet number becomes very high and the spreading vanishes and thus the system is equivalent to PFR.

The main disadvantage of this model is that it can only be used as long as the flow does not deviate greatly from plug flow, i.e. $\frac{1}{P e}$ should remain small.

The peak of the RTD curve obtained by using the axial dispersion model corresponds to $\sqrt{\frac{P e}{4 \pi}}$ (Levenspiel 1999). Hence the optimal peclet number, $P e_{o p t}$, is obtained experimentally as shown in Eq 20.

$$
P e_{o p t} \approx 4 \pi E_{\text {max }}^{2}
$$

The optimal peclet number is the double of $N_{\text {opt }}$.

\section{Results and discussion}

\subsection{Operating conditions}

Two residence time distributions tests were performed on wheat straw. The only difference between the two tests consists in the (theoretical) reactor residence time $\left(t_{\text {reactor }}^{\text {th }}\right)$ that depends on the number of screw pitch $n_{p}$ and on the screw rotation speed $n$ as shown in Eq 21.

$$
t_{\text {reactor }}^{\text {th }}=\frac{n_{p}}{\dot{n}}
$$

The theoretical residence time in test $1\left(t_{1}\right)$ is lower than that in test $2\left(t_{2}\right) . t_{2}$ is $50 \%$ higher than $t_{1}$. In both tests, the biomass had an initial grinding of $20 \mathrm{~mm}$ and the initial acid amount 
and reactor temperature were the same (around $200{ }^{\circ} \mathrm{C}$ ). The dry material flow was $90 \mathrm{~kg} . \mathrm{h}^{-1}$. The different operating conditions are summarized in Table 3.

Table 3 - The used operating conditions.

\begin{tabular}{|c|c|c|c|c|c|c|c|c|}
\hline Test & Biomass & $\begin{array}{l}\text { Initial } \\
\text { grinding } \\
(\mathrm{mm})\end{array}$ & $\begin{array}{l}\mathrm{X}_{\text {acid }} \\
\text { (wt. } \\
\%)\end{array}$ & $\begin{array}{l}\mathrm{X}_{\text {tracer }} \\
\text { (wt. \%) }\end{array}$ & $\begin{array}{l}\text { Mass flow } \\
\left(\mathrm{kg} \cdot \mathrm{h}^{-1}\right)\end{array}$ & $\begin{array}{l}\mathrm{T} \\
\left({ }^{\circ} \mathrm{C}\right)\end{array}$ & $\begin{array}{l}\mathrm{P} \\
\text { (bar) }\end{array}$ & $\begin{array}{l}t_{\text {reactor }}^{\text {th }} \\
\text { (s) }\end{array}$ \\
\hline 1 & & 20 & $0.5-1.0$ & 5.6 & $\underline{90}$ & $\sim 200$ & $10-23$ & $t_{1}$ \\
\hline 2 & straw & & & & & & & $t_{2}$ \\
\hline
\end{tabular}

The particles residence time in the tube from reactor to cyclone is 200 times lower than that in the reactor. The residence time in the cyclone is also much lower than in the reactor.

\section{$4.2 \mathrm{Na}^{+}$concentration}

The concentrations of $\mathrm{Na}^{+}$as function of the time were calculated based on the developed model given in Eq 9. In this section, the focus will be carried out mainly on the concentrations of $\mathrm{Na}^{+}$in the treated biomass - water solutions.

\section{Native biomass conductivity and molar conductivities}

The measured conductivity corresponding to the native biomass (wheat straw) is $\lambda_{\mathrm{NB}}=123$ $\left.\mu \mathrm{S} . \mathrm{cm}^{-1}\right)$. This measurement was performed in the same conditions as for the treated biomass (cf. section 2.5.3 Conductivity and pH measurements), i.e. on the following solution: biomass (10 wt. \%) - water (90 wt. \%). The molar conductivities of the different ionic species were taken from the literature (Vanýsek and Lide 2006) and are given in Table 4. 
Table 4 - Molar conductivities of $\mathrm{Na}^{+}, \mathrm{H}_{3} \mathrm{O}^{+}, \mathrm{CO}_{3}^{2-}$ and $\mathrm{So}_{4}^{2-}$ at $25{ }^{\circ} \mathrm{C}$ (Vanýsek and Lide 2006).

\begin{tabular}{|ll|}
\hline Ionic species & $\begin{array}{l}\text { Molar conductivity } \\
\left(\mathrm{S} . \mathrm{m}^{2} \cdot \mathrm{mol}^{-1}\right)\end{array}$ \\
\hline $\mathrm{Na}^{+}$ & 5.0 \\
\hline $\mathrm{H}_{3} \mathrm{O}^{+}$ & 35.0 \\
\hline $\mathbf{C O}_{3}^{2-}$ & 13.9 \\
\hline $\mathbf{S O}_{4}^{2-}$ & 16.0 \\
\hline
\end{tabular}

\section{Treated biomass}

The raw measurements in the treated biomass - water solutions for test 1 are given in Fig. 2 . The evolution of $\left[\mathrm{Na}^{+}\right]$in these solutions as function of the theoretical residence time $t_{1}$ for tests 1 and 2 is shown in Fig. 3. As previously seen, the concentration of $\mathrm{Na}^{+}$depends on the measured $\mathrm{pH}$ and conductivity. 


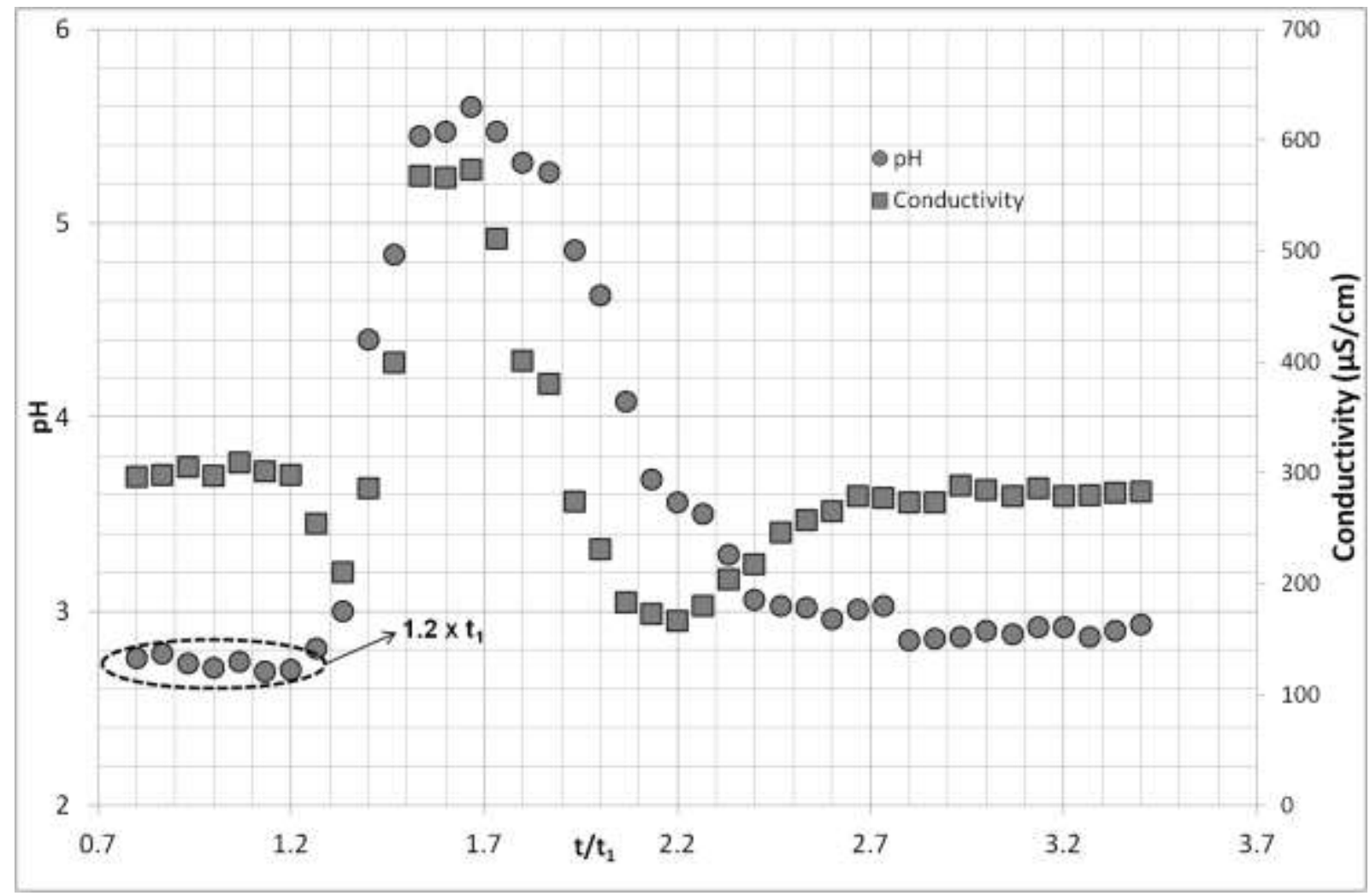

Fig. 2 - The evolution of $\mathrm{pH}$ and conductivity as function of time in the treated biomass water solutions (samples collected at cyclone outlet) - Test 1.

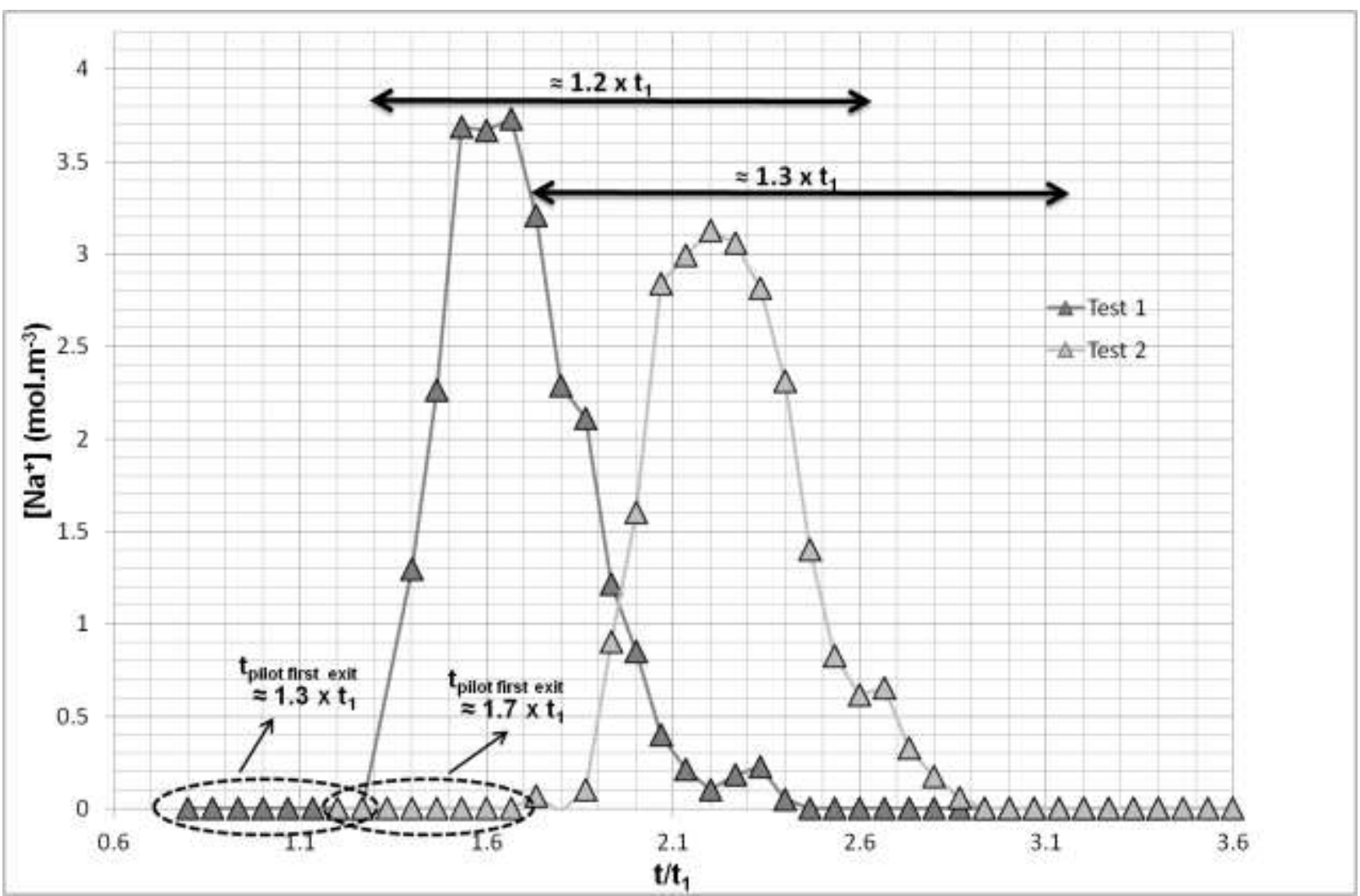


Fig. $3-\mathrm{Na}^{+}$concentration in the treated biomass - water solutions as function of time (samples collected at cyclone outlet) - Tests 1 and 2.

For test $1, \mathrm{pH}$ and conductivity measurements show similar response as the calculated sodium concentrations. The peaks shown in figures 2 and 3 are reached at around $t=1.7 \times t_{1}$.

In Fig. 2, the first exit time out of the reactor/cyclone for test 1 is $1.3 \times t_{1}$. The tracer needs 1.2 $\mathrm{x} t_{1}$ to completely leave the cyclone. Based on $\mathrm{pH}$ and conductivities measurements, the first exit times out of the reactor/cyclone for test 2 is $1.8 \times t_{1}$.

In Fig. 3, the first exit times out of the reactor/cyclone for tests 1 and 2 are respectively $1.3 \mathrm{x}$ $t_{1}$ and $1.7 \times t_{1}$. They are close to the ones found with the raw material measurements. The difference between the first exit times for tests 1 and 2 in Fig. $3\left(0.4 \times t_{1}\right)$ is close to the difference in the theoretical residence times in the reactor for both tests $\left(0.5 \times t_{1}\right) .1 .2 \times t_{1}$ and $1.3 \times t_{1}$ are the required times for the tracer to completely leave the cyclone respectively for tests 1 and 2. It is in agreement to what is observed with the $\mathrm{pH}$ and conductivity $\underline{\text { measurements (cf. Fig. } 2 \text { for test 1). }}$

Fig. 4 represents the variation of $\mathrm{Na}^{+}$concentration as function of time, determined in the aqueous flow for tests 1 and 2. 


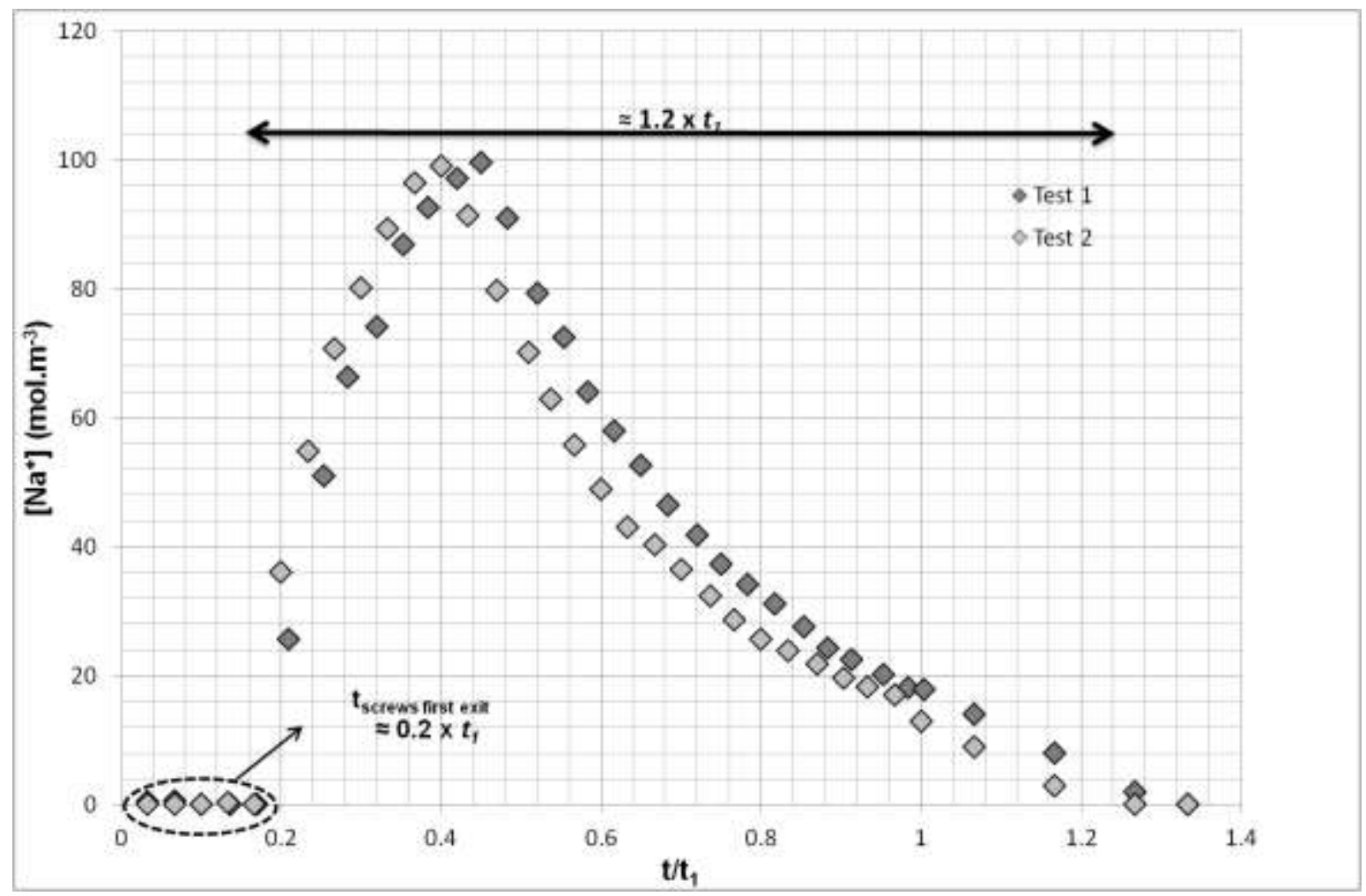

Fig. 4 - Na+ concentration in the aqueous flow as function of time - Tests 1 and 2.

The first exit time of the aqueous flow is $0.2 \times t_{1}$ for both tests. The needed time to exit completely to the aqueous flow is $1.2 \times t_{l}$. The responses for test 1 and 2 are similar because the speed of feeding equipment was not modified.

\subsection{Determination of RTD functions}

In this paragraph, residence time distributions were determined in the reactor (RTD) by using the deconvolution method presented in Eq 11. They were obtained from the aqueous flow and reactor/cyclone signals.

\section{RTD}

The RTD curves determined for tests 1 and 2 are shown in Fig. 5 and Fig. 6. 


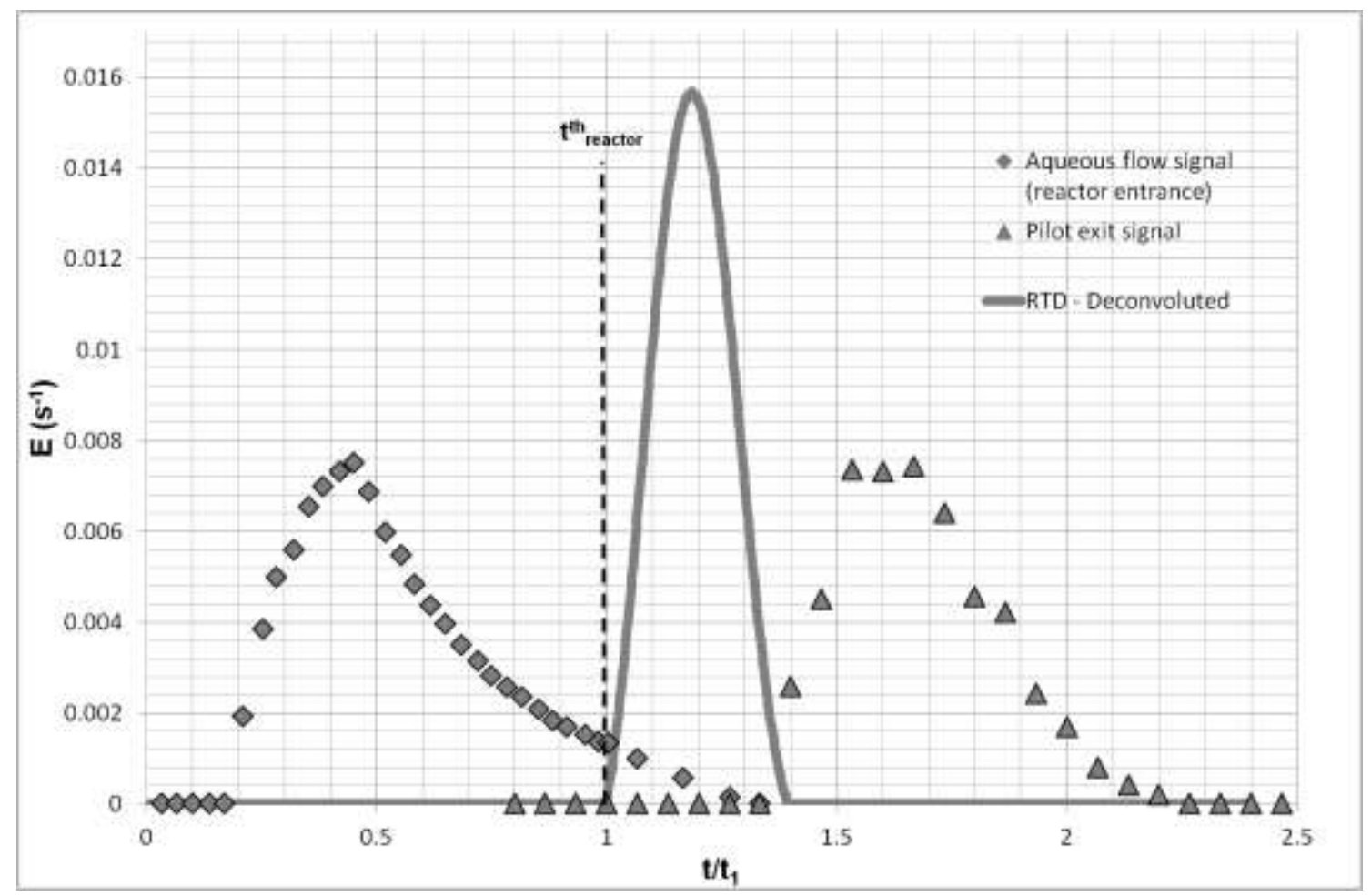

Fig. 5 - Input and output signals and RTD function in the reactor - Test 1.

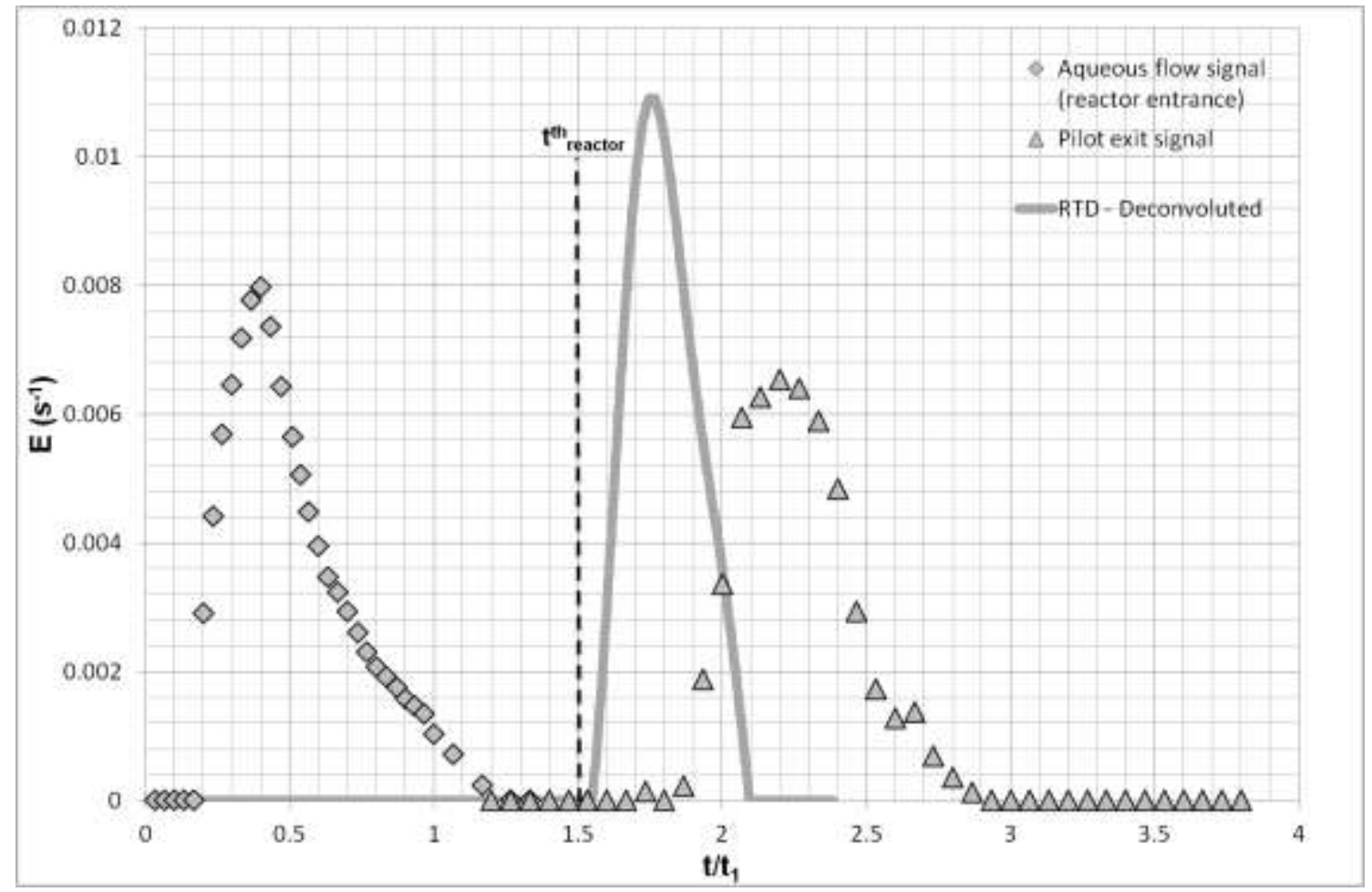

Fig. 6 - Input and output signals and RTD function in the reactor - Test 2. 
It can be observed in Fig. 5 and Fig. 6 that the beginning of the RTD curves correspond for both cases approximately to the theoretical reactor residence time. This means that the theoretical values correspond rather to the minimum residence time than to the mean residence time.

In tests 1 and 2, RTD curve reaches a maximum respectively at $\mathrm{t}=1.2 \mathrm{x} t_{1} \mathrm{~s}$ and $1.7 \mathrm{x} t_{1}$. The gap between these values is $0.5 \times t_{1}$. It is equal to the difference in the theoretical reactor residence time $\left(0.5 \times t_{1}\right)$ between both tests.

\subsection{Mean residence times}

The mean residence times in the reactor for test 1 were calculated based on the deconvoluted RTD functions and on Eq 12. They are given in Table 5.

Table 5 - Mean residence time in the reactor for tests 1 and 2.

\begin{tabular}{|lll|}
\hline Tests & $t_{\text {reactor }}^{\text {th }}(s)$ & $t(s)$ \\
\hline 1 & $t_{1}$ & $\mathbf{1 . 2} \times \mathbf{t}_{\mathbf{1}}$ \\
\hline 2 & $t_{2}$ & $\mathbf{1 . 2} \times \mathbf{~ t}_{\mathbf{2}}$ \\
\hline
\end{tabular}

The mean residence times in the reactors for tests 1 and 2 are about $20 \%$ higher than the theoretical residence times.

By focusing on the RTD functions in Fig. 5 and Fig. 6, it is possible to define then the undercooking zones (A and $\mathrm{A}^{\prime}$ ) and the overcooking zones (B and B') as shown in Fig. 7. In zones A and A', the biomass risks to be not cooked enough and in zones B and $\mathrm{B}^{\prime}$ it risks to be too much cooked. 


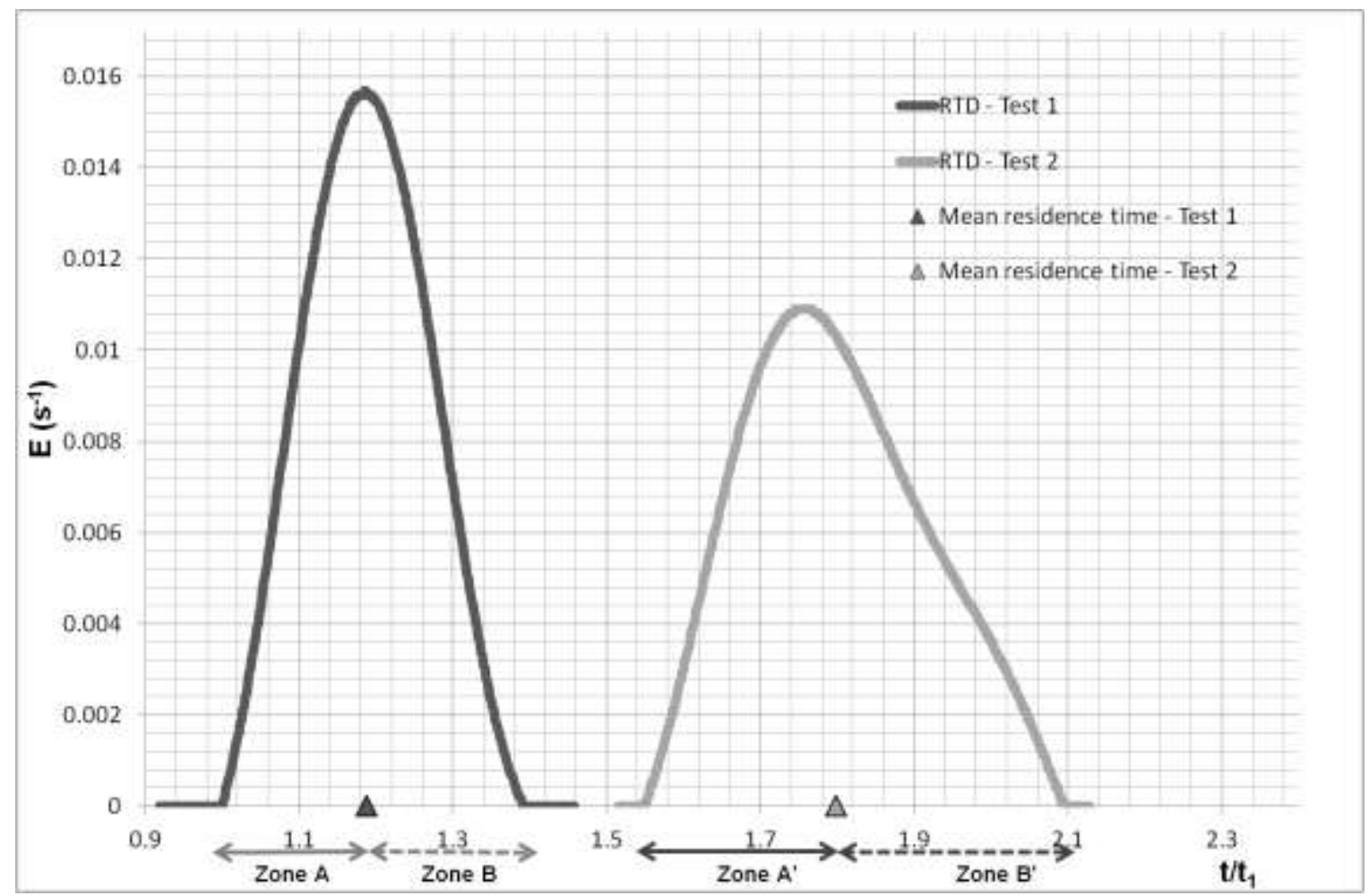

Fig. 7 - Residence time distributions for tests 1 and 2.

In Fig. 7, zones $\mathrm{A}$ and $\mathrm{A}^{\prime}$ for tests 1 and 2 start respectively from $\mathrm{t}=t_{1}$ and $1.6 \times t_{1}$ and end at the mean residence time of each test. Zones B and B' begin from each test's mean residence time and last respectively till $\mathrm{t}=1.4 \mathrm{x} t_{1}$ for test 1 and $2.1 \times t_{1}$ for test 2 . In perfect plug-flow reactors, these zones should be as small as possible.

In order to well underline both zones and well compare the tests, it is better to represent instead the dimensionless RTD curves as function of the dimensionless time (Fig. 8). 


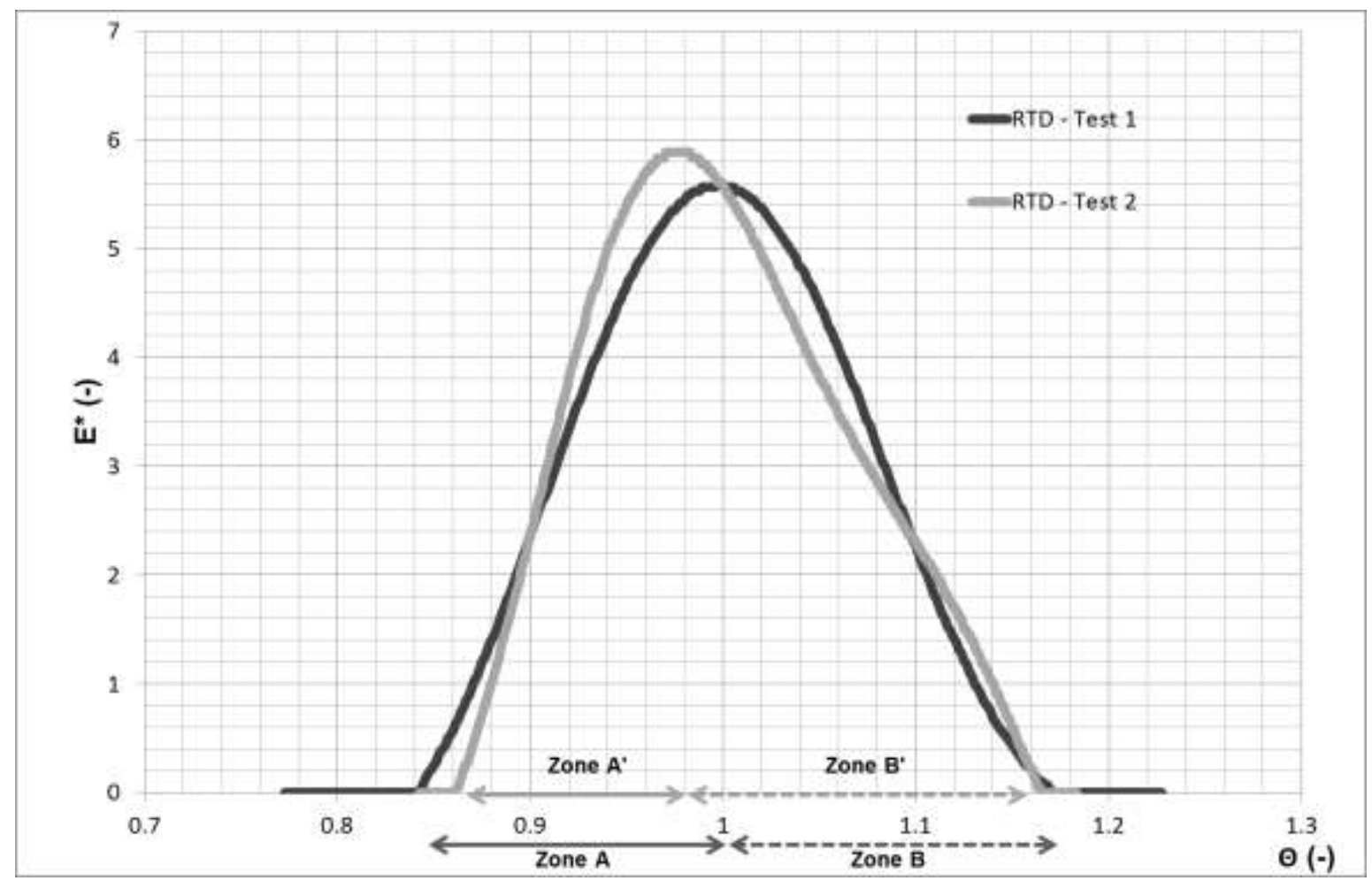

Fig. 8 - Cooking efficiency for tests 1 and 2 - Dimensionless parameters.

As seen in Fig. 8, both dimensionless RTD curves are close to each other. The residence time distributions are almost homothetic. For test 1 , zone A and B are respectively located between 84-100 \% and 100-117\% of the dimensionless mean residence time. As for test 2, zones A' and $\mathrm{B}^{\prime}$ are respectively within the following ranges: $86-100 \%$ and $100-116 \%$ of the dimensionless mean residence time.

\subsection{Comparison of RTD models}

Residence time distributions in the reactor (RTD) were compared to the CSTR in series (Eq 14) and ADM models (Eq 18). As previously mentioned, these models can be adjusted as function of the amount of continuous flow stirred reactors $N$ or the Peclet number $P e$. The results are shown in Fig. 9. 


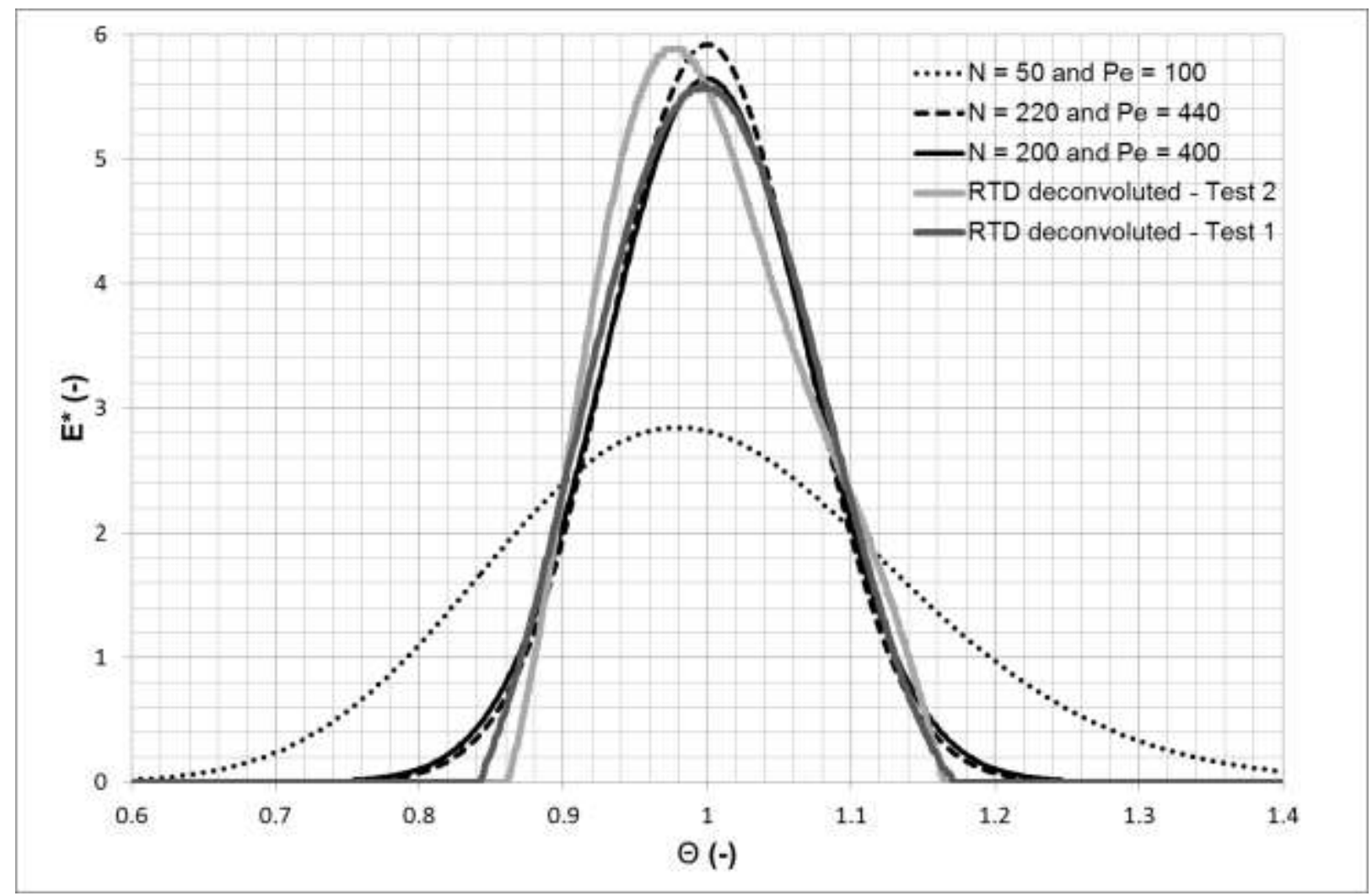

Fig. 9 - Comparison of the CSTR and ADM models with RTD curve- Test 1.

As seen in Fig. 9, CSTR and ADM models can predict well the RTD curves when using respectively high $N$ and $P e$ values. For CSTR model: $N_{o p t}=200$ (test 1 ) and $N_{o p t}=220$ (test 2). For ADM model: $P e_{o p t}=400$ (test 1) and $P e_{o p t}=440$ (test 2). The optimum value of $N$ is half of that of $P$ e (cf. 3.3.2 axial dispersion model). These high values of $N$ and $P e$ show that the reactor has a nearly plug-flow behaviour which is in agreement to what is found in the literature (Levenspiel 1999). The theoretical residence time in the reactor is calculated by equation 22 which assumes that the product moves forward one screw pitch at each rotation. But in fact there is a sliding effect which makes the product progression slower.

For test 1 , the variance and skewness are respectively of $\sigma=6.5 \cdot 10^{-2}$ and $\gamma=5.7 \cdot 10^{-2}$ (regardless of the model). They are around $\sigma=6.410^{-2}$ and $\gamma=27.610^{-2}$ for test 2. 
The dimensionless standard deviation is almost the same for the two tests. For normal distributions, we could say that $95.5 \%$ of the product has a residence time varying between $\pm /-2 \sigma$ which is in our case about $+/-13 \%$. Despite the curves (Fig. 8) are not Gaussian, this is comparable to the $\min / \max$ values of about $+/-15 \%$.

The skewness of test 2 is much larger than for test 1 which corresponds to a more dissymmetric curve. But the skewness value should be interpreted carefully in view of the experimental imprecision and the data analysis (deconvolution).

\section{Conclusion}

In order to perform residence time distribution experiments in a biomass pretreatment pilot for second generation biofuel, we propose a new protocol which uses sodium carbonate as tracer. It was selected as a tracer because of the corrosivity and risk on humans of the other potential (neutral) tracers. Due to the reaction between the tracer and the acidified biomass, a novel methodology was developed. It consists mainly in measuring the $\mathrm{pH}$ and the electrical conductivity at two different locations of the pilot: reactor entrance (aqueous flow) and reactor exit. Then, a chemical model was developed allowing the sodium concentrations in the aqueous flow and at the reactor exit to be determined from the measured conductivities and $\mathrm{pH}$. Following this protocol, the signals were deconvoluted providing the RTD functions and allowing the determination of the mean residence time in the reactor. The RTD of the pretreatment reactor is close to the one of a plug-flow reactor because the deviation is only about $\pm 15 \%$. Afterward, the experimental RTD functions were compared to two different models: CSTR in series and ADM. Residence time distributions in the reactor were well represented by using these models with respectively high amounts of continuous flow stirred reactors and Peclet numbers $(\mathrm{N} \sim 200$ and $\mathrm{Pe} \sim 400)$. This emphasizes once more the nearly plug-flow behaviour of the reactor. This work allows better understanding of thermal 
treatments in the reactor that can be used for better sizing and development of future screws and reactors for biofuels applications. The new protocol developed in this work can also be used for any pretreatment pilot of lignocellulosic biomass.

\section{Ackowledgements}

This work was supported by Futurol project and by BPI France. 


\section{References}

Arellano, M., et al. (2013). "Experimental study and modelling of the residence time distribution in a scraped surface heat exchanger during sorbet freezing." Journal of Food Engineering 117(1): 14-25.

$\mathrm{Bi}, \mathrm{C}$. and B. Jiang (2009). "Study of residence time distribution in a reciprocating single-screw pinbarrel extruder." Journal of Materials Processing Technology 209(8): 4147-4153.

Danckwerts, P. V. (1953). "Continuous flow systems. Distribution of residence times." Chemical Engineering Science 50(24): 3857-3866.

Danckwerts, P. V. (1979). "Commentary from Current Contents." Chemical Engineering Science 50(24): 3855.

Davis, M. E. and R. J. Davis (2003). Fundamentals of Chemical Reaction Engineering. New York, McGraw Hill.

Gao, J., et al. (1999). "Residence-time distribution model for twin-screw extruders." AIChE Journal 45(12): 2541-2549.

Gupta, M., et al. (2004). "Flow Characterization of Moving and Stirred Bed Vacuum Pyrolysis Reactor from RTD Studies." Chemical Engineering Research and Design 82(1): 34-42.

Ileri, R. and Y. Muslu (1996). "Unsaturated flow phenomena in porous medium as in a trickling filter." J. Chem. Tech. Biotechnol 66: 25-34.

Jeantet, R., et al. (2008). "Residence time distribution: A tool to improve spray-drying control." Dairy Sci. Technol. 88: 31-43.

Kumar, A., et al. (2015). "Conceptual framework for model-based analysis of residence time distribution in twin-screw granulation." European Journal of Pharmaceutical Sciences 71: 25-34.

Lee, S. M., et al. (2005). "In-line measurement of residence time distribution in twin-screw extruder using non-destructive ultrasound." Korea-Australia Rheology Journal 17(2): 87-95.

Lee, Y. Y., et al. (1999). "Dilute-acid hydrolysis of lignocellulosic biomass." Adv. Biochem. Eng./Biotechnol. 65: 93-115.

Legile, P., et al. (1991). "Détermination du temps de séjour des particules dans un lit fluidise gazsolide par traçage magnétique." Powder Technology 66: 69-74. 
Levenspiel, O. (1999). Chemical reaction engineering, John Wiley \& Sons.

Moreno, M. D. (1990). "A tracer study of the hydraulics of facultative stabilization ponds." Water Research 24(8): 1025-1030.

Mosier, N., et al. (2005). "Features of promising technologies for pretreatment of lignocellulosic biomass." Bioresource Technology 96(6): 673-686.

Nachenius, R. W., et al. (2015). "Residence time distributions of coarse biomass particles in a screw conveyor reactor." Fuel Processing Technology 130: 87-95.

Sievers, D. A., et al. (2016). "Online residence time distribution measurement of thermochemical biomass pretreatment reactors." Chemical Engineering Science 140: 330-336.

Vanýsek, P. and D. R. Lide (2006). CRC Handbook of Chemistry and Physics, CRC Press.

Wyman, C. E. (1999). Biomass ethanol: technical progress, opportunities, and commercial challenges. Ann. Rev. Ener. Environ. .

Xi, Y., et al. (2015). "Flow characteristics of biomass particles in a horizontal stirred bed reactor: Part I. Experimental measurements of residence time distribution." Powder Technology 269: 577-584. 